\title{
On Managing the Enterprise Information Systems Transformation: Lessons learned and research challenges
}

\author{
Charles Møller
}

Dept. of Accounting, Finance and Logistics, Aarhus School of Business, Fuglesangs Alle 4 DK-8210 Aarhus, Phone: +4589486361, charles@asb.dk

\begin{abstract}
Contemporary standardized Enterprise Information Systems, like SAP or Oracle, are increasingly setting the agenda and the pace for the development of almost any organization. Most organizations today are required not only to establish effective business processes but they are also required to accommodate for changing business conditions at an increasing rate. The major vendors are proposing new breed of technology, sometime denoted extended ERP or ERP/II. Consequently the time is ripe to reflect on the status of Enterprise Information Systems and their application in practice. This paper reflects on the lessons learned from managing the Enterprise Information Systems transformation and outlines future challenges for research on Enterprise Information Systems. The paper concludes that the ERP industry has a significant and increasing impact on enterprises due to the EIS enable transformation of the business. Consequently, the practical implications of these results are the continued management of EIS, after going-live, but most important, EIS research need to refocus and embrace this new tendency. The paper takes an exploratory perspective on managing the EIS transformation by examine the evidence from the experience gained in seven different Danish organizations. The paper finally outlines the critical implications for research in EIS.
\end{abstract}

\section{Introduction}

Contemporary standardized Enterprise Information Systems (EIS), like SAP or Oracle, are increasingly setting the agenda and the pace for the development of almost any organization. Few IT innovations have had as much impact on business organizations in recent years as the Enterprise Resource Planning (ERP) systems. ERP systems are standardized software packages that can be configured to manage every aspect of an organization within any business.

It is estimated that organizations worldwide have spent around USD18.3 billion every year on ERP in recent years [1]. The adoption of ERP is often explained as phases or waves [2]. During the first phase of ERP, the organizations struggle to implement ERP and get the internal processes in place. There has been a lot of interest in and critique of ERP based on the experience from this phase, but recently attention has now shifted from implementation issues towards post-implementation issues. During a "second wave" implementation the organizations deploy their new systems in order to create and sustain competitive advantage.

Most organizations today are required not only to establish effective business processes but they are required to accommodate for changing business conditions at

Please use the following format when citing this chapter:

Møller, C., 2006, in International Federation for Information

Processing, Volume 205, Rescarch and Practical Issucs of Enterprisc Information Systems, eds.

Tjoa, A.M., Xu, L., Chaudhry, S., (Boston:Springer), pp.307-317. 
an increasing rate. Many business processes extend beyond the boundary of the enterprise into the supply chain and the information infrastructure therefore is critical. The rationales of integrating ERP and SCM have been explored by Tarn, Yen and Beaumont [3]. They conclude that the industrial trend is that ERP is becoming a subclass of a much larger and broader enterprise business system or in more general terms Enterprise Information Systems (EIS).

A recent published survey shows that the factors most associated with achieving value from ERP are integration, process optimization and use of the ERP systems in decision-making [4]. Davenport and Brooks [5] argue that ERP systems are internally focused, but the greatest impact of ERP is felt in the supply chain.

Today nearly every business relies on their Enterprise Information System for process integration and the future generations of Enterprise Information Systems will increasingly be driven by business process models [6].

Consequently, businesses must face up to the continuing challenge of balancing the transformation of the organization towards processes in the supply chain driven by an ongoing change in the standard EIS and emerging business disruptions.

This presents a major managerial challenge. This paper takes an exploratory perspective on managing the EIS transformation by examine the evidence from the experience gained in seven different Danish organizations. In the next chapter the paper establishes a framework for understanding the Enterprise Information Systems transformation and then the paper presents an analysis of the cases. Finally the paper summarizes the lesson learned and discusses the implications for future research.

\section{The Enterprise Information Systems transformation}

The notion of standard EIS/ERP systems has developed drastically during the last five years due to the impact of the web technologies, among other things. In order to fully comprehend the systems it is necessary to look at the industry in a 50-year retrospective.

The industrial Enterprise Resource Planning (ERP) market showed a positive growth in 2003 after years of decline, precipitated by the Y2K craze. The worldwide market for ERP solutions to discrete and process manufacturers was USD 9.10 billion in 2003 and is forecasted to be over USD 12.00 billion in 2008, growing at a Compounded Annual Growth Rate (CAGR) of 5.7 per cent over the next five years, according to a recent ARC Advisory Group study.

The concept of EIS has often been explained through the evolution of ERP [7-9]. The concept of Enterprise Information Systems (ES) has evolved over almost fifty years, driven by the changing business requirements, new technologies and software vendors' development capabilities.

ERP is a standardized software package designed to integrate the internal value chain of an enterprise. An ERP system is based on an integrated database and consists of several modules aimed at specific business functions.

The ERP II concept is a vision originally conceived by Gartner Group in 2000. Gartner Group, who also tagged the ERP concept, define ERP II as "a business strategy and a set of industry-domain-specific applications that build customer and 
shareholder value by enabling and optimizing enterprise and inter-enterprise, collaborative-operational and financial processes"[10].

ERP II includes six elements that touch on the business, the applications and technology strategy: (1) the role of ERP II, (2) its business domain, (3) the functions addressed within that domain, (4) the kinds of processes required by those functions, (5) the system architectures that can support those processes, and (6) the way in which data is handled within those architectures. With the exception of architecture, these ERP II elements represent an expansion of traditional ERP [10]. ERP II includes [11]: Supply Chain Management (SCM); Customer Relationship Management (CRM); Supplier Relationship Management (SRM); Product Lifecycle Management (PLM); Employee Lifecycle Management (ELM) and Corporate Performance Management (CPM). So in conclusion, ERP II is essentially componentized ERP, e-business and collaboration in the supply chain.

Throughout the ERP industry this new philosophy of ERP and e-business has been gradually incorporated into the ERP systems and the system architectures were redesigned and modularized, e.g. like SAP intends it with the NetWeaver platform, like Oracle intends with the Fusion platform, and like Microsoft intend with their Dynamics platform. Therefore the contemporary standard systems do incorporate ERP II. The ERP industry survived the challenge and recent market analyses do not render any signs of market fragmentation.

Today all the major vendors have adopted the ERP II concept, either partly or fully. The evolution is driven by emerging business requirements and new information technology as it has been argued in the preceding chapters was the case of the evolution of ERP.

It has been argued that people, structure, realignment and change management will prove more important to fulfilling the ERP II vision [12]. In all the cases in this study the process change was the main driver of the second-wave projects and most important, the ERP II concepts has enabled the transformation of the ERP systems into general EIS driven by process models [6].

\subsection{The ERP market and the adoption of ERP}

The ERP market and the vendors are important not just because of their systems, but because their research reports and the vendors' consultants have an enormous impact on the business decisions made in companies adopting ERP. The ERP market is however quite complex for the following reasons [13]:

First, The ERP market is not well-defined. Sometimes it includes all kinds of enterprise application software and sometimes only ERP. The total 2002 revenue of the ERP vendors was USD 20 billion according to AMR Research, but the total ERP spending may be 5-10 times higher.

Second, there are significant commercial interests in defining, segmenting and measuring the market. The authoritative sources of market sizes and segments are large research organizations such as Gartner, IDC, AMR Research or Forrester.

Third, the market is quite dynamic. The vendors are constantly merging and consolidating. Since the Gartner Dataquest report was published, Peoplesoft bought 
JD Edwards, Oracle bought Peoplesoft and Microsoft acquired Encore and tried to buy SAP. Finally the systems are constantly developed, and some of them are discontinued.

A different perspective on the ERP market is the enterprise perspective: what systems do they have, what do they invest in, and when do they acquire or update their systems?

A recent survey on ERP in large Danish Enterprises [13] concluded that (1) ERP has become a pervasive technology; (2) ERP has become a contemporary technology; (3) the ERP market has matured; and (4) the dominant ERP strategy is still the single vendor strategy. The study was based on telephone interviews with ERP managers in 88.4 per cent of the top-500 enterprises in Denmark.

ERP has been adopted by Danish enterprises in general. 93.4 per cent of the large companies had an ERP of some kind, and 13.6 per cent of the enterprises had more than one ERP system. Only 6.6 per cent of the companies have not adopted ERP, their financial performance is poor, and their number is decreasing.

ERP is the pervasive infrastructure because it is so widely adopted. Based on the high percentage of adopters and based on the non-adopters' accounts we conclude that ERP as a technology is a prerequisite to run any business, and that it should be considered an infrastructure rather than a new technology.

ERP is a contemporary technology because the installed base is renewed frequently. Based on the average age of the systems ( 2.8 years), it is concluded that the ERP technology now follows the normal IT lifecycle. There are differences, however: the in-house developed ERP systems are still to be considered a legacy technology. The overall conclusion is that the latest releases and technologies are available to in the enterprises and is waiting to be used.

ERP adoption is stable, because the market is consolidated. Based on the adoption level, the vendors' market shares and the average systems' age, it is concluded that the ERP market has matured. Indications are that we end up with one (SAP), maybe two or three major vendors, a handful of global vendors, and a small number of vendors specializing in specific industries or countries. A similar pattern was found among the systems suppliers and implementation consultants. This was further reinforced by the fact that on average ERP investments are below 1 per cent of the revenue. However, it can not be concluded that the ERP market is no longer innovative.

ERP adoption is converging towards a dominant design due to the facts mentioned above. Only 13.6 per cent of the companies use more than one ERP vendor. This indicates that the businesses pursue a "single-vendor" strategy rather than a "best-of-breed" strategy. Consequently, the new ERP II functions are provided by the major vendors' systems, and add-on modules or third part bolt-on systems may only have a limited scope. This may imply that supply chain planning will be dominated by, e.g. SAP APO (Advanced Planning and Optimization) modules, and consequently that the reference models provided by the major vendors will be the future supply chain templates. This might imply that the variety in the applied logistics concepts is reduced to the standards defined by the major vendors. However, it can not be concluded that inter-organizational integration will be much 
easier with enterprises using the same platforms.

The general conclusions of the survey is that large companies now have a common platform based on the large vendors (in particular SAP) and that the platform is kept up to date with the most recent release.

\subsection{A framework for EIS transformation}

ERP enables close cooperation among supply chain partners facilitating suppliercustomer interactions and minimizing transaction costs [3]. However, there is a risk of ERP actually hampering progress in SCM [14]. Nonetheless, it is becoming clear that the greatest impact of, and payback from, EIS is in SCM [4].

ERP researchers recognize the time-gap between impact and effect [15]. The benefits from EIS implementation are best understood in a lifecycle perspective. Several authors applied a lifecycle view on ERP implementation [16]. The proposed lifecycle models $[9,17$, and 18] all emphasize the pre-implementation phase, have fewer details on the post-implementation phase and almost nothing on the use of EIS. Ross and Vitale (2000) describe an ERP journey as a prisoner's escape. The last stages: continuous improvement and transformation are sometimes referred to as second wave or the post-implementation stages. It is in the post-implementation stages we find the impact of ERP in the supply chain.

Table 1. Overview of the cases, Adopted from [19]

\begin{tabular}{|l|l|l|l|}
\hline Context & Problem & Solution & Issues \\
\hline Lego Company & $\begin{array}{l}\text { Inability to change due to } \\
\text { Legacy system complexity }\end{array}$ & $\begin{array}{l}\text { Quick small scope SAP } \\
\text { implementation }\end{array}$ & $\begin{array}{l}\text { New adaptive supply } \\
\text { chain strategy }\end{array}$ \\
\hline $\begin{array}{l}\text { Municipality of } \\
\text { Copenhagen }\end{array}$ & $\begin{array}{l}\text { Ineffective administrative } \\
\text { procedures }\end{array}$ & $\begin{array}{l}\text { Oracle implementation } \\
\text { using two waves }\end{array}$ & $\begin{array}{l}\text { Decentralized IT } \\
\text { competencies }\end{array}$ \\
\hline $\begin{array}{l}\text { Martin } \\
\text { Professional }\end{array}$ & $\begin{array}{l}\text { Legacy systems and new } \\
\text { management }\end{array}$ & $\begin{array}{l}\text { Rapid Baan } \\
\text { implementation }\end{array}$ & $\begin{array}{l}\text { The need to enhance } \\
\text { functionality }\end{array}$ \\
\hline $\begin{array}{l}\text { Dell Computer } \\
\text { Automotive } \\
\text { Structures }\end{array}$ & Failed SAP ERP project & $\begin{array}{l}\text { EIS based on EAI } \\
\text { backbone }\end{array}$ & $\begin{array}{l}\text { World class make-to } \\
\text { order process }\end{array}$ \\
\hline $\begin{array}{l}\text { Bang \& } \\
\text { Olufsen }\end{array}$ & $\begin{array}{l}\text { Heavy customized legacy } \\
\text { system }\end{array}$ & $\begin{array}{l}\text { SAP implementation } \\
\text { with } \\
\text { "best practice" }\end{array}$ & $\begin{array}{l}\text { Support of planning } \\
\text { process }\end{array}$ \\
\hline $\begin{array}{l}\text { Fritz Hansen } \\
\text { ElS platform based on } \\
\text { "best-of-breed" }\end{array}$ & $\begin{array}{l}\text { Increasing number of } \\
\text { supplier due to outsourcing } \\
\text { mgmnt with suppliers }\end{array}$ \\
\hline
\end{tabular}




\subsection{Cases}

Lego Company is the well-known toy manufacturer. Before launching their ERP project Lego had a large number of legacy systems throughout their supply chain. The ERP project was accelerated due to poor financial results of 2000 . One of the reasons was the inability of the existing supply chain to adapt to market demands. The major part of Lego's annual sale to consumers takes place at Christmas. With the existing supply chain set-up, Lego was unable to respond to market dynamics. During 2000 a large-scale project aimed at replacing the existing systems with a custom -built ERP system based on standardized global processes and Oracle was introduced. By the end of 2000 the project was abandoned and replaced with a new project based on standard SAP. This project was concluded successfully in 2001 with a new ERP platform called LEGO Light. This project was followed by a number of second wave projects aimed at improving process effectiveness. Lego topmanagement has highlighted ERP with an IT and process-governance structure, which include sourcing considerations. The new projects are driven by the people from the ERP implementation team by with an emphasis on the combination of process development and IT.

The municipality of Copenhagen $(\mathrm{KK})$ is one of the largest organizations in Denmark with 43.000 employees (FTE). KK implemented Oracle almost ten years ago. The first wave was oriented primarily towards the back-office function of financial control. In $2001 \mathrm{KK}$ initiated a second-wave project aimed at eprocurement and project management, among other things. One of the challenges was that these projects touched on the more marginal actors in the supply chain. For instance actors like small daycare centers and their suppliers, who previously acted independently from KK, were now included in the scope of the EIS. KK approached this project by setting up a team focused on process development - not as an IT implementation project. Consequently the change was managed as a learning process, but following the standardized new EIS processes. This enabled KK not only to implement the new modules but also to unleash the energy of new ideas for improvement.

Martin Professional develops and manufactures intelligent lighting for the entertainment and architectural markets. The founder of Martin, a charismatic entrepreneur was replaced by professional management in 1999 when the success and growth was about to choke the company. Since the existing legacy systems (very rudimentary systems) could not cope with $\mathrm{Y} 2 \mathrm{~K}$, an ambitious plan for implementing a new ERP platform based on Baan was launched in 90 days. With some disruption the ERP system was in place throughout the group by the end of 2001 when Martin started their venture into second generation projects. This, of course, included new modules but also a lot of different "best-of-breed" systems, like Business Intelligence (BI), Supply Chain Management (SCM) and many others. It also included the implementation of a different ERP platform (Axapta) in the sales companies forcing Martin to reconsider and unify their EIS architecture. One of the problems is integration issues when deploying more platforms.

Dell took a different approach to integration in the supply chain. Dell set out 
early in the nineties with an ambitious SAP project. In the mid-nineties Dell abandoned the ERP path after some heavy investments resulting only in a functional HR system. Dell developed a new strategy called G2 where they specified the architecture of the EIS in Dell's supply chain. The essence of this architecture is an EIS based on Enterprise Application Integration. The outcome of this strategy is Dell's ability to rapidly deploy new business models and closely coordinate and integrate with partners in the supply chain.

Hydro Automotive Structure (HAS) is a first-tier supplier in the automotive supply chain. HAS is part of the Hydro Group; they develop and manufacture aluminum components for the automotive industry. As a supplier HAS have limited influence on the business model and must conform to the requirements of the dominating actors. In 1999 HAS replaced an old industry-specific system and was facing a group policy on SAP as a preferred vendor. Due to the cost and resource requirements of a SAP project, HAS selected Axapta from Microsoft Business Solutions and a small local consulting company to run the implementation. After a long-winded implementation process, the system was operative in 2000 and HAS started their quest for process improvements. Today they have developed a highperforming, integrated supply chain and they are, for example, able to track and trace every piece of material. A lot of the process improvements are actually not a result of the ERP system (e.g. KANBAN) but HAS are convinced that the ERP system has provided the platform for the improvements.

Bang \& Olufsen (B\&O) is a manufacturer of high-end audio/video equipment for the consumer market. $\mathrm{B} \& \mathrm{O}$ has been through a long phase of process improvements due to a near-fatal financial situation in the eighties. This includes outsourcing a high number of activities and therefore $B \& O$ depend quite heavily on their supply network and have developed exceptional partnerships with suppliers and customers over the years supported by in-house developed IT systems. Y2K made B\&O decide to replace their customized legacy system with SAP. The implementation of the finance and HR modules went very well but logistics and production planning presented considerable problems. B\&O developed "Mass-Customization"-inspired processes for manufacturing customer-unique products, and the implementation of SAP would jeopardize this process. When B\&O had to make a stock announcement on an expected loss due to problems with SAP, they got SAP's full attention leading to the development of a $\mathrm{B} \& O$ solution which later became part of the standard system. Today B\&O is a happy SAP user seeing it as a strategic platform for B\&O's development. Recently they have started integrating the supply chain planning further by using the APO (Advanced Planning and Optimizer) module.

Fritz Hansen $(\mathrm{FH})$ is a manufacturer of exclusive design furniture. The furniture includes designs from architects such as Arne Jacobsen and Piet Hein. FH has used Movex, an ERP system from Intentia, since 1993; in 2000 they decided to upgrade their systems. FH used to be a traditional furniture manufacturer but due to the success of designer furniture they were forced to outsource a number of activities. Also they put an emphasis on demand management. Consequently supply chain coordination was high on the agenda, and modules like product configuration and supplier management were critical to FH. FH's EIS ended up as a combination of an 
ERP system, a CRM (Customer Relationship Management) system and a data warehouse. As a consequence of the new EIS platform $\mathrm{FH}$ has been transformed from a traditional manufacturing company to a decentralized, process-oriented organization where collaboration takes place across the entire supply chain. In particular the use of smaller suppliers to create flexibility is mainly a result the ERP platform.

\subsection{Lessons learned}

The cases are alike in the sense that the motivation for introducing ERP was almost identical. Y2K combined with a need for a common platform drove management to move into ERP. Also the expected benefits from ERP conform to Ross and Vitale's motivations for ERP [18]. The cases also report on serious stabilization issues, for some organizations it was measured in years, but the cases render interesting insight into the post-implementation stages.

The research literature on implementation e.g. Ross and Vitale[18] has little details on their "transformation stage" and none of the companies in their study felt that they had yet transformed themselves. In a workshop for logistics managers in large Danish enterprises the relationship between ERP and SCM was emphasized. The observations were quite similar to those in a Dutch Delphi study[14]. The managers responsible for the supply chain pointed out that although the ERP systems were the key to future supply chain developments the inherent inflexibility of ERP was also a major roadblock for SCM initiatives.

The organizations' general reflection was that the second-wave projects were oriented towards process improvements, and therefore the organizational dimension is emphasized. A second observation is that the second-wave project took the organizations places they never intended to go. The second generation projects were aimed at the supply chain but the new EIS suddenly opened roads that the organizations initially did not consider. Their new ERP systems became instrumental in this change.

This suggests a more subtle relationship between the business, the EIS, and the supply chain processes, where the EIS holds the potential to leverage (or to destroy) business opportunities. Consequently, the time is now ripe for a new management perspective on EIS.

\subsection{Implications for managing Enterprise Information Systems}

Enterprise Information Systems are under constant development. Current ERP systems reflect fifty years of aggregated business requirements and innovations. Future EIS, ERP II or whatever they evolve into, will continue this evolution. Consequently the contemporary standard systems from one of the major vendors will include extended functions for integration supply chain processes. Based on the retrospective analysis it is also feasible that future critical requirements will be provided in the standard systems and thus will be made available to existing users as a part of normal upgrades.

Based on the survey data it can be concluded that large enterprises have the most 
recent EIS from the major vendors. Also the age profile of the installations can lead to the conclusion that EIS is a technology that is kept up-to-date with the most recent release. Then it is feasible to deduce that the overall EIS architecture is determined by the architects of the major vendors.

The case studies exemplify the impact of EIS architecture on the supply chain. The cases all illustrate the staged development approach. A few years after the initial ERP implementation effort, when the ERP infrastructure is in place, the focus of the development extends into the supply chain. The driver of this change is effectiveness in the supply chain, which is very specific to the organizations, but informationbased collaboration is central to all the cases.

These arguments suggest that many organizations are facing transformation triggered by EIS adoption. This transformation is a new kind of IT diffusion process based on standardized EIS and "best-practice" processes. Until now, mainstream ERP research has mainly focused on isolated issues in this transformation. The new diffusion process goes beyond the traditional system lifecycle thinking, and the implementation phase is just an intermezzo in the transformation. What is proposed here is that the enterprise transformation is considered in relation to the ERP market and the evolution of EIS.

The implications of the EIS transformation for practice are enormous. If the technology and processes acquired by the EIS impact the supply chain, managing the transformation is of strategic importance. This paper therefore proposes a new area of management, EIS Management and Innovation. Except during implementation, IT and ERP is not considered top management issues, and supply chain development is considered logistics and operations management responsibility. This paper suggests that SCM and ERP are to be considered in tandem. EIS Management and Innovation is a new challenge and an issue that needs to be brought to the attention of top management.

Another issue is EIS as a source of process innovation. Before acquiring an ERP system, an organization typically spends a good deal of resources in evaluating the suitability of the standard processes of the system and the strategic match. What happens after a few years? The new releases are accepted more or less as a routine or based on operational criteria. Who is responsible for the strategic evaluation of the new features, and who initiates a decision to discontinue an EIS? This should be the challenge of the EIS Manager.

\section{Conclusions}

The paper proposed that EIS implementation based on standardized EIS and "bestpractice" processes lead to a new management challenge: Enterprise Information Systems Management and Innovation. The argument is rooted in seven case studies, a survey on ERP adoption and a retrospective analysis on the development of EIS. The paper discussed the emerging issues and the implications for management.

Having reviewed the ERP research literature little support for this new challenge has been found, and we propose that EIS management and innovation is explored and put on the research agenda. 
This paper contributes to ERP research by exhibiting the importance of ERP management. The paper draws a direct line from the achieved benefit in the supply chain, second-wave ERP projects to ERP implementation and to EIS development. Consequently ERP can be considered a source of innovation in the supply chain.

The research implies that the ERP industry itself is to be considered an object for further research. The ERP industry contributes significantly to the value chain and to EIS transformation of the enterprises.

ERP research has not dealt explicitly with this diffusion process. Many authors have dealt with ERP implementation, a few authors have dealt with the ERP journey, but no one has considered the EIS transformation process in all entire aspects. Many enterprises are now organizing their ERP activities towards second-wave projects. This will present many new practical challenges as well as research challenges. In future managers must be prepared to manage EIS - or the large vendors will set the agenda for them.

\section{References}

1. Shanks, G., Seddon, P.B., Willcocks, L.P. (eds.): Second-Wave Enterprise Resource Planning Systems. Cambridge University Press, Cambridge (2003)

2. Willis, T.H., Willis-Brown, A.H.: Extending the value of ERP. Industrial Management + Data Systems 102 (2002) 35-38

3. Tarn, J.M., Yen, D.C., Beaumont, M.: Exploring the rationales for ERP and SCM integration. Industrial Management + Data Systems 102 (2002) 26-34

4. Davenport, T.H., Harris, J.G., Cantrell, S.: Enterprise systems and ongoing process change. Business Process Management Journal 10 (2004) 16-26

5. Davenport, T.H., Brooks, J.D.: Enterprise systems and the supply chain. Journal of Enterprise Information management 17 (2004) 8-19

6. Dumas, M., Aalst, W.M.P.v.d., Hofstede, A.H.M.t.: Process-Aware Information Systems: Bridging People and Software through Process Technology. (John Wiley \& Sons Inc. 2005)

7. Chen, I.J.: Planning for ERP systems: Analysis and future trend. Business Process Management Journal 7 (2001) 374-386

8. Klaus, H., Rosemann, M., Gable, G.G.: What is ERP? Information Systems Frontiers 2 (2000) 141-162

9. Markus, M.L., Tanis, C.: The Enterprise Systems Experience-From Adoption to Success. In: Zmud, R.W. (ed.): Framing the Domains of IT Research: Glimpsing the Future through the Past. Pinnaflex Educational Resources, Inc, Cincinnati, OH (2000) 173-207

10. Bond, B., Genovese, Y., Miklovic, D., Wood, N., Zrimsek, B., Rayner, N.: ERP is dead Long Live ERP II. GartnerGroup (2000).

11. Møller, C.: ERP II: a conceptual framework for next-generation enterprise systems? Journal of Enterprise Information Management 18 (2005) 483-497

12. Weston, E.C.T.: ERP II: The ext. Enterprise System. Business Horizons 46 (2003) 49-55

13. Møller, C.: Unleashing the Potential of SCM: Adoption of ERP in Large Danish Enterprises. International Journal of Enterprise Information Systems 1 (2005) 39-52

14. Akkermans, H.A., Bogerd, P., Yücesan, E., van Wassenhove, L.N.: The impact of ERP on supply chain management: Exploratory findings from a European Delphi study. European Journal of Operational Research 146 (2003) 284-310

15. Shang, S., Seddon, P.B.: Assessing and Managing the Benefits of Enterprise Systems: the Business Manager's Perspective. Information Systems Journal 30 (2002) 38-46 
16. Rosemann, M.: Enterprise System Management with Reference Process Models. In: Shanks, G., Seddon, P.B., Willcocks, L.P. (eds.): Second-Wave Enterprise Resource Planning Systems: Implementing for Effectiveness. Cambridge University Press (2003)

17. Bancroft, N.H., Seip, H., Sprengel, A.: Implementing SAP R/3: How to introduce a large system into a large organization. (Manning, Greenwich 1997)

18. Ross, J., Vitale, M.: The ERP Revolution: Surviving Vs. Thriving. Information Systems Frontier 2 (2001) 231-241

19. Rikhardsson, P., Møller, C., Kræmmergaard, P.: ERP Enterprise Ressource Planning Danske erfaringer med implementering og anvendelse. Børsen Bøger, København (2004). 